\title{
Predictive analytics in management of enterprise logistics innovations
}

\author{
Darya Ivanova \\ Department of logistics and supply chain management \\ St. Petersburg State University of Economics \\ St. Petersburg, Russian Federation \\ darpalna@yandex.ru
}

\begin{abstract}
This research explores a modern approach for defining innovation. Reference has been taken, in particular from the latest publication of Oslo Manual, where innovation has been divided into two parts: product innovation and innovation of business processes.

A combined option for the dissemination and exchange of information and data processing has been suggested. It proposes the building up of information flows drawn towards each other and their consolidation into a single information resource. Finally, an applicable program-targeted approach is suggested for management of logistics innovations in enterprises.
\end{abstract}

The importance of predictive analytics within the framework of program-targeted approach for management of logistics innovations in enterprises has been shown. The reason is the change in use of information by the enterprises and emergence of a large amount of data which is to be processed for taking management decisions.

Three aspects of invariance in application of predictive analytics have been defined, while managing logistics innovations in micro logistics systems: from the viewpoint of type of business; from the viewpoint of task setting and solution and from the viewpoint of the nature of logistics innovations.

A conclusion has been made for the need of dividing all data into two types: internal and external, depending on their relation to the logistics system of any enterprise.

The scheme has been drawn to exercise predictive analytics step by step in management of logistics innovations in enterprises with a program-targeted approach.

The invariance in application of predictive analytics while managing logistics innovations in micro logistics systems has been proved and its necessity has been defined.

Keywords - Logistics innovations, predictive analytics, program-targeted approach, big data, digitalization

\section{I.INTRODUCTION}

The term "innovation" which first appeared in the $19^{\text {th }}$ century in scientific research of culture experts, has undergone major changes. Initially, it meant introduction of certain elements from one culture into another (usually, it referred to infiltration of traditions and organization methods from European societies into traditional Asian and African societies).

Joseph Schumpeter is considered to be the founder of innovation theory and he discussed innovation (new combinations) as entrepreneurial means of gaining profit in his book "The theory of economic development" [1].

In the last few decades many changes have taken place which has resulted in changing the definition and classification of the term innovation. According to the new revision by International standard of measuring scientific, technical and innovation activities "Innovation is a new or improved product or process (or a combination thereof) that differs significantly from previous products or processes and which has been provided to potential users or was put into operation (process) [2]. Compared to the previous revision, the number of innovation types has also changed, as identified by this definition. Instead of four types identified in 2006 (product, process, organizational and marketing), now there are two main types: product innovation and innovation of business processes (Fig.1).

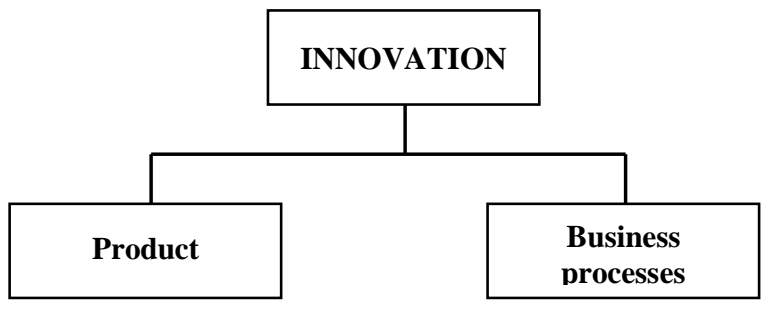

Fig.1 Innovation typology according to a new revision of Oslo Manual

As per the above typology, the logistics innovations, which are, first of all, management type innovations that may also lead to appearance of technological innovations [3], can be referred to innovations of business processes. In the conditions of The Fourth Industrial Revolution the fundamental directions of logistical innovations are closely related to informatization and digitization [4, 5]. Studies on digital globalization [6] show that in recent years the flows of physical goods and finances have decreased in comparison with the flows of data and information. With the development of digital informational products, the cost of cross-border communications and transactions decreases; this enables the enterprises to remain in constant touch with their suppliers and consumers, irrespective of the distance. The interaction of contractors on digital platforms in the supply- chain has lowered the barriers for participating in the market, and this has enabled the small and medium business enterprises to compete in the global market [7]. 
In this respect it is necessary to remark that the information support started playing a defining role in carrying out innovative activities in business enterprises. In view of the fact that if an enterprise carries out innovation activities in the right direction it will lead to improvement in the labor productivity of its workers, reduction in the cost of work in hand, in organizing the production of new goods and services, in optimization of the work undertaken, the activities of all the participants in the process in question must be well coordinated. In our view, to achieve this it is the most suitable way to employ a combined variant of exchange and dissemination of information and data analysis; this may lead to building up of information flows in both directions, and their consolidation and formation of a single information resource. In case the creation and functioning of an effective system of control and incentives has been achieved, the application of this option will allow for the development and implementation of logistics innovations at enterprises at a faster pace, simplify the search and selection of counterparties in the implementation of economic relations, reduce time and financial costs, etc.

What is more, such variant of dissemination of information corresponds to the program-targeted approach to management of logistics innovations at enterprises; this approach assumes the correlation between strategic goals and planned goals for formulation and introduction of innovative projects which in turn are related to organization's resources with the help of programs. The effectiveness of such an approach in adopting logistics innovations by enterprises depends upon, on one hand, timely exchange of information (not only within the organization but also with the outside world), and, on the other hand, this exchange determine it. In view of the above-mentioned trends of increase in volume of information flows it becomes all the more important to not only collect the data but also perform its qualitative analysis and processing, for making management decisions at various stages of development and introduction of logistics innovations. One of the possible tools of solving these types of problems may be the predictive analytics.

\section{II.MATERIALS AND METHODS}

The purpose of the present study is to prove the necessity and invariance in application of predictive analytics while managing logistics innovations in micro logistics systems. The goal is achieved on the bases of a systematic approach. In the course of study of the given task, common scientific methods and special actions were used such as: description, comparative analysis, general conclusion, comparison, structure grouping and systematization.

\section{III.RESULTS}

Usually, the term "predictive analytics" is used to describe the totality of analytics and statistical methods of forecasting future actions or behaviors. In the business processes the predictive analytics is the instrument, which is necessary for revealing and modeling all possible variations of sequence of events. Based on the statistical models, it helps to reveal regularities between data of past and current periods and to determine potential risks and possibilities.
Predictive analytics includes such actions as: information collection and processing, analysis and visualization of the data of conducted studies; also, it includes development of forecasts and data models, application of predictive models, evaluation and/or prediction of future results $[8,9]$. At enterprises the importance of predictive analytics in the framework of programtargeted approach to logistics innovations management is conditioned by the transformation of use of information by the enterprise, as well as by the large volume of data which must be processed for making management decisions. It must be noted that in the past the analytical methods were used for studying the enterprises and their business processes, and for finding causeeffect relations for some events. But nowadays, thanks to development of different information and digital data collection solutions and thanks to analysis and processing of large volume of data, there are possibilities to choose such an innovative direction which would create a competitive advantage and enable to win the competitive struggle [10].

\section{IV.DISCUSSION}

The program-targeted approach to logistics innovations management in micro logistics systems causes the necessity to look into the invariance of application of predictive analytics.

First, the invariance depends on the type of activities of an enterprise introducing logistic innovations (production, trade, finance, consulting and others).

According to experts on predictive analysis, the scope of its application is quite wide: from political campaigns to research in medicine, etc. [11]. At production enterprises predictive analytics can be applied for introducing logistics innovations in the process of working out of new products, upgrading of product lines, selection of contractors (suppliers, agents, logistic providers, potential consumers and others) and optimization of production process itself. It must be emphasized that the predictive nature of analytics gets a new significance while making a decision "Make or Buy": during repair and maintenance activities at production enterprises ( either to order a required part from a foreign supplier and to wait for its delivery or to print it out on a 3-D printer, etc.). The potential profit by using such an approach consists in: cost minimization of store holding by $20-50 \%$, reducing machine idle time by $30-50 \%$, and rise in prediction accuracy by $85 \%$ [12].

As for the activities of trading enterprises, the instruments of predictive analytics allow them to raise customer-responsive focus by analysis of consumer basket and applying programtargeted logistics innovations, considering individual needs of this or that consumer (segmentation of consumers). Besides, considering peculiarities of functional cycles of trading enterprise logistics, predictive analytics facilitates an integrated task solution at all its stages (purchasing logistics, in-store logistics, sales and service logistics and reversing flow logistics).

Second, while managing logistics innovations the nature of usage of means and methods of predictive analytics is inevitably connected with the contents and volume of set tasks at one or the other stage of interaction of economic operator/subjects. Their decision will allow optimizing logistics processes at the enterprise.

If we look into the application of predictive analytics in supply chains with regard to integrated optimization of activities 
of cooperating entities, we can come to a conclusion of the need of dividing whole data volume into two types: external and internal, depending on their relation to logistics system of either enterprises. At the same time, depending on the nature of its content, external data (in other words - external informational flow) can be divided into the following:

- $\quad$ received from the supplier (or sent to supplier);

- $\quad$ received from users (or targeted at the user);

- received from agent (or sent to agents) including logistics agents.

Furthermore, depending on their regularity internal informational flow of enterprise's logistics system can be divided into the following:

- structured: data base, several types of reports (annual, quarterly, current etc.);

- unstructured: information received via email, social networks etc.

It is important to point out that both internal and external informational flows observed in relation to business logistical system can be divided into internal and external, depending on their direction.

Innovational development tasks set in the enterprises can be solved smoothly when collection and processing of all data types and means of predictive analytics are combined within a framework of a single digital platform.

Third, the invariance of predictive analytics has to be examined considering the nature of logistics innovations themselves.

According to the report "Digital economics: global trends and Russian business practice", the main "digital drivers" in managing the supply chains or supply base (material technical facilities) are:

- unmanned or/ and automated vehicles and drones

- different types of sensors and transmitters, carrying out operational control and management of commodity and service flow (movement).

- 3-D printing.

In this respect it is expected that the average share of expenses of supply base in domestic (national) enterprises, using maximum digital technologies will be $0.22 \%$ from their net profit. Whereas, the less progressive competitors not implementing digital technologies will note about $0.5 \%$ share of expense [13].

At the same time, foreign specialists point out in the report "Globalization in transition: the future of trade and value chains", that the share of logistics expenditures (including costs related to custom clearance, loading and unloading activities in ports etc.) in production and sale chains are quite high. They see that the solutions to this problem lie in application of a wider range of technology [7]. In particular, digital platforms as a means of uniting many participants make a trans-border search and future coordination of contractors much more effective. At present electronic trade markets have already provided wide transborder flow by use of predictive analytics means, aggregation of huge samples, matching and increase in price formation transparency. According to studies, by the year 2020 trans-border sales of B2C electronic trading will reach about $\$ 1$ trillion. At the same time, B2B electronic trading can actually be much higher [14]. Despite the fact that many of these deals can replace "traditional" trade flows, electronic trading can stimulate offline trade growth by $\$ 1.3-2.1$ trillion by the year 2030 , due to increase in trade volume of production and technical goods by $6-10 \%$. On the other hand, a faster growth of small party trade will create difficulties in custom clearance.

Apart from this, examples of progress in logistical technology are given in the above study. Also instances of tasks which can be solved more effectively by their application are mentioned. Particularly, it is noted that as a result of development of the Internet of things (IoT) expansion of opportunities will happen in regard to organization and management of goods delivery by tracking it in real time. The specialists estimate that by the year 2025, the annual input of the IoT in the world economy may amount to US \$ 4 to 10 trillion [12]. Again, Artificial Intelligence will allow planning and carrying out transportation via optimal routes, taking into account the aim of transportation, delivery points, lowering of risks and route safety, besides traffic information. Automated documentation processing expedites custom clearance of goods at checkpoints. Autonomous transport vehicles, if used in ports, may conduct cargo handling operations, warehousing and reloading of containers much faster and with fewer errors. The use of the Blockchain technology in supply and sale activities minimizes the time of carrying out transit delivery and expedites the payment process [15].

The study says that, in case of integrated use of abovementioned technologies the time of shipping and custom clearance will be decreased by $16-28 \%$. The share in overall trade (online and offline) will increase by $6-11 \%$ by the year 2030 [7].

On the other hand, the analysts of DHL Company have analyzed the evolution of logistics and have studied the main tendencies of world markets. They have outlined 28 trends of logistics innovation development in the coming years and have divided them into two big groups with 14 trends in each group [16]:

1. Social and business trends (green logistics, omnichannel, logistical market places, Sharing Economy and others);

2. Technological trends (3D- printing, artificial intelligence, augmented reality, big data analysis, cloud logistics, blockchain, IoT, robotization and automatization, digital twin and others).

Together with achievements in various fields such as digital platforms, robotics, Blockchain, Internet of Things (IoT), additive technologies (3D-printing), cloud technology the analytic models will actively help in reducing transactional and logistical delays, global supply-chain will become smarter, faster, more stable and oriented towards the consumers.

It must be remarked that management solutions in view of logistics innovations adopted by enterprises can be effective only in those cases where the predictive analytics have been integrated with the structure of the entire analytic process. This makes it convenient for usage and enables any user to have an instrument at each level of organizational structure of the management of the enterprise and at each stage of management of logistics innovations. 
For a successful performance of predictive analytics in managing logistics innovations within the framework of program-targeted approach the following sequence of actions is recommended (Fig. 2):

1. Setting of the goal and formulation of the problem which must be solved to achieve it;

2. Collecting data from different sources;

3. Data processing and analysis;

4. Development of a predictive model (different variants of predictive models);

5. Estimation of the suggested model;

6. Model implementation;

7. Monitoring its effectiveness.

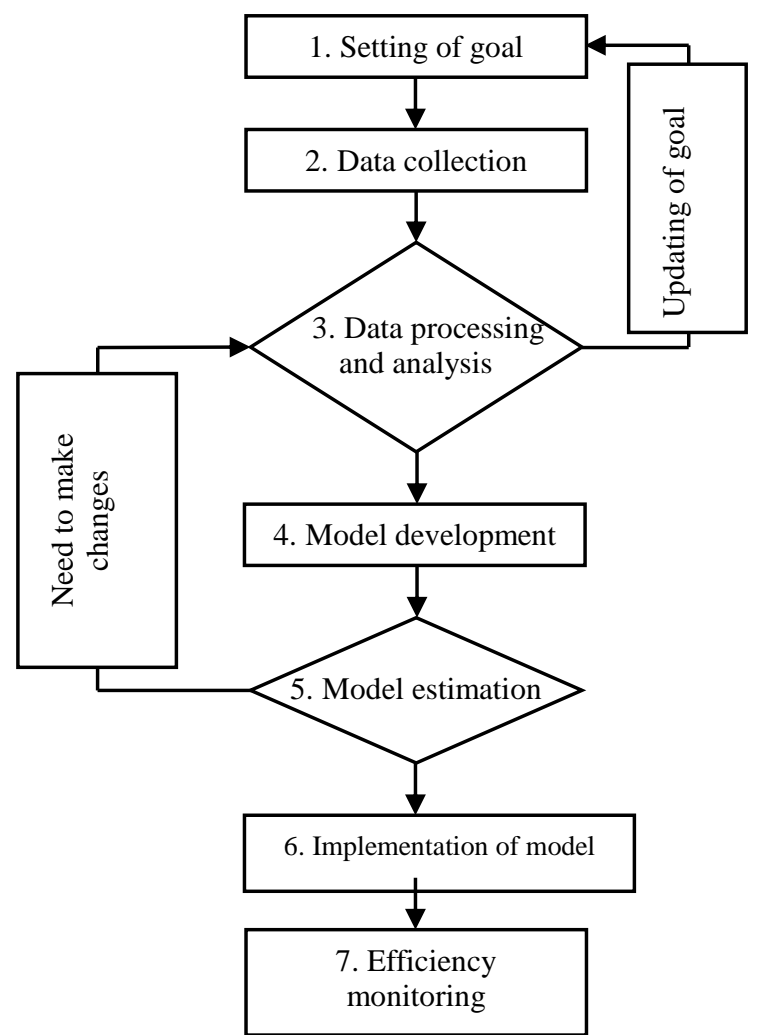

Fig. 2 Stages of implementing predictive analytics in management of logistics innovations at enterprises in the framework of program-targeted approach

It is necessary to note that as it was suggested the implementation of the predictive analytics is to be divided into stages, and this action will allow (the enterprise) to make goal and task setting clearer, and make any changes timely.

Also, it is assumed that the last stage "Efficiency monitoring" for one model can become a reference point for information collection and analysis with the aim of development and introduction of the other improved model. This way, the process of applying means of predictive analytics in management of logistics innovations will become cyclic.

\section{V.CONCLUSION}

The following patterns were detected in the course of domestic and foreign research, and also practice of managing logistics innovations in the micro logistics systems:

First, despite the increase in absolute reading of production volume, with the development of digital platforms there is a tendency of decrease in the offline trade market.

Second, the service trade is leaving behind the goods trade in material-physical form.

Third, due to the introduction of technology of The Fourth Industrial Revolution into the logistics processes and due to their full or partial automation there is a decrease in labor expense during the last decades.

Fourth, the logistics processes in enterprises are becoming more knowledge-intensive, due to the need for continuous updating in order to increase competitiveness.

Fifth, there is the problem of collecting, processing, analyzing and storing data in connection with their everincreasing volumes.

That is why enterprises are forced to change constantly while adapting to market scenario. For this they use trans-border flows of data and new technology, including digital platforms, IoT, automatization and Artificial intelligence.

At present, predictive analytics is emerging into one of the most important trends in corporate analytics, which is used in solving a wide range of problems, including problems of logistics nature. It is conditioned by the aspirations of enterprises and organizations to develop and increase competitive advantage by introducing new innovative technologies in their logistics processes. As the studies have shown, logistics innovations at present have become more technological and include large volumes of data, computing capacities, computer software, etc. All of this, in its turn helps the enterprises to compete successfully on account of analytical innovations.

\section{REFERENCES}

[1] J. Schumpeter, the Theory of Economic Development, Translated into Russian from German, Izd-vo "Progress", Moscow 1982, 456p.

[2] OECD/Eurostat(2018), Oslo Manual 2018: Guidelines for Collecting, Reporting and Using Data on Innovation, $4^{\text {th }}$ Edition, The Measurement of Scientific, Technological and Innovation Activities, OECD Publishing, Paris/ Eurostat, Luxemburg .[Electronic Source]: URL: https://doi.org/10.1787/9789264304604-en : (Consulted on 29.06.2019)

[3] D. P. Ivanova, Goal-oriented approach to management of logistical innovations in business enterprises, Dissertation for Candidate of Economic Sciences 08.00.05, St. Petersburg State University of Economics, St. Petersburg 2017, 222p.

[4] K. Schwab and N. Davis, Shaping the Fourth Industrial Revolution, Translated into Russian from English Eksmo, Moscow 2018, 320 p.

[5] K. Schwab, The Fourth Industrial Revolution, Translated into Russian from English, Izdvo "E", 2017, 208 p.

[6] Digital globalization: The new era of global flows / McKinsey Global Institute, March 2016 [Electronic Source] URL: https://www.mckinsey.com/ /media/McKinsey/Business\%20Functions/Mc Kinsey\%20Digital/Our\%20Insights/Digital\%20globalization\%20The\%20n ew\%20era\%20of\%20global\%20flows/MGI-Digital-globalization-Fullreport.ashx (Consulted on 02.07.2019)

[7] Globalization in transition: The future of trade and value chains / McKinsey Global Institute, January 2019 [Electronic Source]: URL: https://www.mckinsey.com/ /media/McKinsey/Featured\%20Insights/Inno vation/Globalization $\% 20 \mathrm{in} \% 20$ transition $\% 20 \mathrm{The} \% 20$ future $\% 20 \mathrm{of} \% 20 \mathrm{trad}$ e\%20and\%20value\%20chains/MGI-Globalization-in-transition-The-future- 
of-trade-and-value-chains-Executive-summary.ashx (Consulted on 01.07.2019)

[8] Danniel.D.Gutierrez, Inside BIGDATA, A handbook on the predictive analytics [Electronic Source]: URL: http://www.spotfiretibco.ru/wpcontent/uploads/2017/09/InsideBIGDATA.pdf (Consulted on 27.06.2019)

[9] V. Mayer-Schonberger, Big Data: A revolution that will change the way we live, work and think, Translated into Russian from English by I.Gaidyuk, Mann, Ivanov and Ferber, Moscow 2014, 240p

[10] B. Franks, The Analytic Revolution: How to Improve Your Business By Making Analytics Operational In The Big Data Era, Translated into Russian from English, Alpina Publisher, Moscow, 2016, 316 p.

[11] Kucherova, K., Mescheryakov, S., Shchemelinin, D. Using predictive monitoring models in cloud computing systems (2018) 919, pp. 341352.

[12] Digital Russia: A new reality / Digital McKinsey [Electronic Source]. URL:

https://www.mckinsey.com/ru/ /media/McKinsey/Locations/Europe\% 20and\%20Middle\%20East/Russia/Our\%20Insights/Digital\%20Russia/ Digital-Russia-report.ashx (Consulted on 27.06.2019)

[13] The Digital Economy: Global trends and Russian business practices, [Electronic Source]. URL: http://www.vcpp.ru/media/1181/tsifrovayaekonomika-globalnye-trendy-i-praktika-rossiyskogo-biznesa.pdf. (Consulted on 27.06.2019)

[14] The Global B2B E-commerce Market Will Reach 6.7 Trillion USD by 2020, Finds Frost \& Sullivan: [Electronic Source]. URL https://ww2.frost.com/news/press-releases/global-b2b-e-commercemarket-will-reach-67-trillion-usd-2020-finds frost-sullivan/ (Consulted on 07.07.2019)

[15] G. Yu. Silkina and V. V. Shcherbakov, The Modern Trends in Digital Logistics, Politekh-Press, St. Petersburg 2019, 237 p.

[16] Logistics Trend Radar. Version 2018/19 // DHL Trend Research: [Electronic Source]. URL: https://www.logistics.dhl.ru/ruen/home/insights-and-innovation/insights/logistics-trend-radar.html (Consulted on 27.06.2019) 